\title{
CINEMATICAL ANALYSIS OF THE PRE-TAKING AND PRE-COMPACTING MECHANISMS OF SOME GARBAGE TRUCKS

\author{
GHEORGHE VOICU* ${ }^{* 1}$, MIRCEA LAZEA ${ }^{1}$, BIANCA-STEFANIA ZABAVA ${ }^{1}$, \\ PAULA TUDOR ${ }^{1}$, VICTOR MOISE ${ }^{1}$
}

POLITEHNICA University of Bucharest, Splaiul Independentei 313 Bucharest, Romania

\begin{abstract}
The paper presents several constructive variants of power systems and makes a comparative analysis of them, both constructively and functionally. The kinematic analysis of a bar and lever mechanism is also realized, which is used in a wide range of compaction by translation. Elucidation of the movement of the working organs of these mechanisms is necessary for a good understanding of their operation, but especially for redesigning and improving their functional parameters for a low loss and low energy operation.
\end{abstract}

Keywords: municipal solid waste, compaction mechanism, garbage truck

\section{INTRODUCTION}

The volume of solid waste generated in urban areas is increasing along with population growth, higher levels of consumption and greater use of packaging by industry. In developing countries and countries with economies in transition, waste management often emerges as a problem that endangers human health and the environment $[1$, 2]. Managing solid waste is one of the most costly urban services, typically absorbing up to 1 per cent of GNP and 20 to 40 per cent of municipal revenues in developing countries.

Solid waste management provides employment for up to 6 workers per 1,000 population - a figure that could represent up to 2 per cent of the national workforce. Even so, the service is frequently inadequate, with more than half the refuse generated in urban areas remaining uncollected, and large areas of cities receiving no regular attention [3]. The responsibility for providing a solid waste management service generally rests on local government, and a common and fundamental deficiency is the failure of governments to ensure that sufficient funds are available to provide an acceptable level of service.

The equipment for compacting and transporting municipal solid waste (MSW) is in most cases placed on car chassis for the collection from the producers. Most municipal waste collection machines perform translation compaction and feed systems are disposed at the rear of the machine. These take up the waste disposed of from smaller containers ( 240 or 1100 liters) and transfer them to the container of the car, eventually making a precompaction due to their operation.

Vehicles intended for the collection and transport of household waste must ensure their fast loading without scattering, dust and noise, as well as a closed shipment of waste and rapid discharging at a payload factor to enable the vehicle to operate at the parameters the most economical. They must be equipped with continuous forwarding devices towards the end of their collecting and distribution compartment, be of a simple and reliable construction with a maximum safety factor in service and comply with valid public road traffic regulations

Construction of these systems is different, from one machine manufacturer to another, but the operating principle is relatively similar.

\footnotetext{
* Corresponding author, email: ghvoicu 2005@yahoo.com
}

(C) 2019 Alma Mater Publishing House 
The operation of these systems is achieved by means of hydraulic cylinders connected to the hydraulic system of the machine, in many cases it is necessary to synchronize the operation of several such hydraulic cylinders From a mechanical point of view, the feeding systems of the waste collection machines are some mechanism with bars and levers articulated with motion in the longitudinal - vertical plane of the car, with little spatial movement.

Most waste trucks, use rear-mounted compaction systems, with complex motion compaction plates that take the waste from the bunker into the collection container. The waste is compressed by the compaction mechanism on a mobile ejector plate that gradually moves under the pressure of the waste, thus maintaining a constant pressure on them. For unloading the solid waste, the rear part is lifted with the help of hydraulic cylinders, and the pressure plate pushes the waste from the back of the vehicle [3].

The aim of the paper is to present several constructive variants of power systems and makes a comparative analysis of them, both constructively and functionally. The kinematic analysis of a bar and lever mechanism is also realized, which is used in a wide range of compaction by translation.

\section{MATERIALS AND METHODS}

The translation compaction systems shall be used stationary or with mobility (located on a autochassis) in the case of specific vehicles. The process of compaction (pressing) of waste takes place in 3 phases:

- material feed of the waste collection tank;

- $\quad$ successively compacting in the compression room;

- $\quad$ unloading of compacted material.

In case of translating compaction systems, the density of the material is about $250-350 \mathrm{~kg} / \mathrm{m}^{3}$ for wet waste MSW, and $175-250 \mathrm{~kg} / \mathrm{m}^{3}$ for dry waste (recyclable).

If the final compaction and discharge system is roughly the same in most of the translation-compacting waste collection machines, with load on the back the supply and pre-compaction system has countless constructive variants. It is intended to retrieve waste from small containers $\left(0.24,1.1\right.$ or $\left.4 \mathrm{~m}^{3}\right)$ and to lift and push over previously deposited waste into the room compression.

Household and commercial wastes in the wealthier and more industrialised countries have very low densities, typically between $100 \mathrm{~kg} / \mathrm{m}^{3}$ and $150 \mathrm{~kg} / \mathrm{m}^{3}$. As a result, compaction mechanisms in the collection vehicles are commonly used to compact the wastes so that an economic load can be carried on the truck within the limits of the truck body dimensions.

Usually, after compaction the waste densities are increased to 400 or even $500 \mathrm{~kg} / \mathrm{m}^{3}$ so that the volume reduction (waste compaction) ratio is $4: 1$ or even $5: 1$.

The benefits of using compactor trucks in developing countries are generally as follows [3]:

- compactor trucks are able to carry economic payloads in situations where the wastes have a density which is too low to enable a full load to be carried in a non-compaction truck;

-they are readily available. Compactor trucks are produced in large numbers for local applications in industrialised countries, so these vehicles can be supplied with a relatively short delivery time, and the manufacturers are eager to sell as many as possible;

- they have a sophisticated and modern appearance, pleasing to mayors and other city officials;

- the waste is largely enclosed. Some liquids resulting from compaction may escape and trucks that have not been washed often emit a very unpleasant smell, but little waste escapes when the truck is moving;

-loading is fast and convenient.

For the equipment shown in Figure 1, the working positions and parts of the supply and compaction system are show in Figure 2. These positions are somewhat characteristic of most of these mechanisms.

In the first position, the waste collection and pressing plate is in a high position and its lateral brackets are in a secluded position, allowing the supply of fresh hopper waste. It follows the position, the yoke is in the lowered position towards the back of the whole machine. In the next position, the hydraulic pressure cylinders of the pressure plate are closed by lifting the waste from the hopper over the previously deposited waste and in the last 
position of the mechanism, the yoke presses the high waste and makes the vertical compaction plate in the trucks system move slightly below the waste pressure. After this, the pressure plate of the power mechanism shall be withdrawn in the initial position and the feeding and compaction process shall resume until the entire dump is filled.

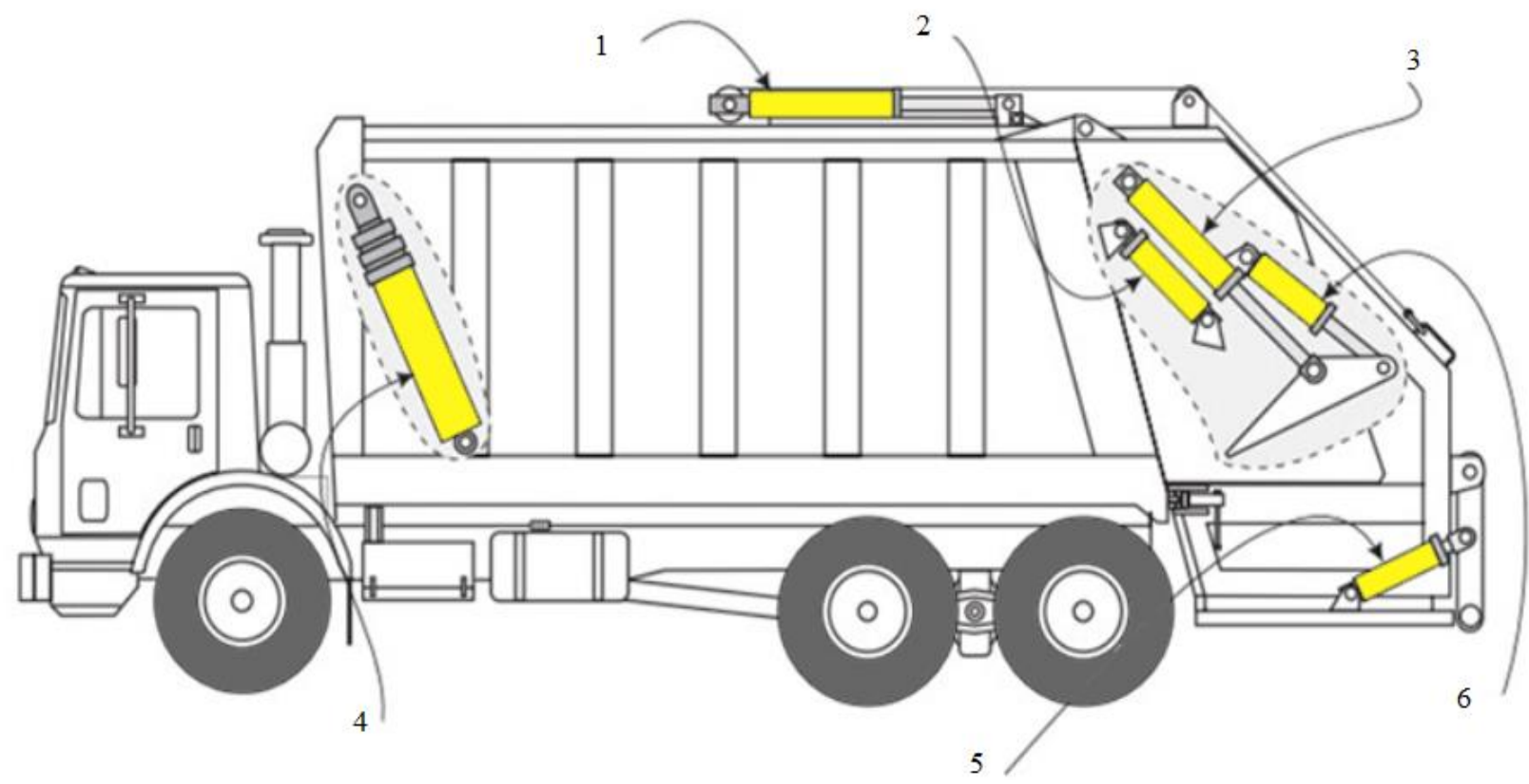

Fig. 1. Technological diagram of garbage truck with translation compaction system [4]: 1. overhead container lift winch/ reeving; 2. tailgate raise; 3. blade slide/ link outside packer; 4. ejector push out; 5 . arm or roll bar container/ dumper; 6. blade/ sweep/ panel inside packer.
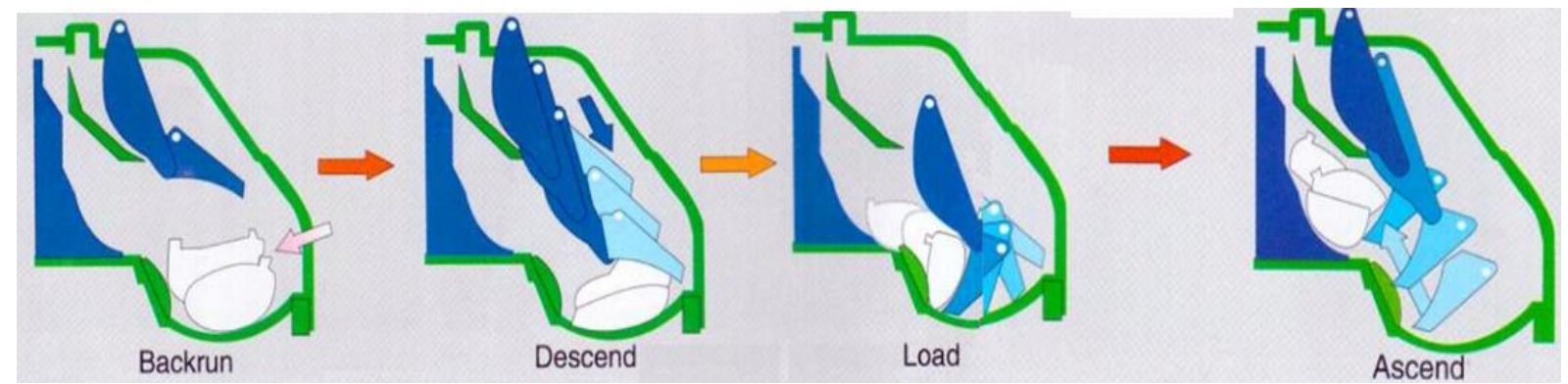

Fig. 2. The compaction mechanism of a municipal waste collection machine (Value) [5].

When emptying, the vehicle receiving part is folded and the emptying plate actuated by the telescopic hydraulic cylinder moves the material to the rear of the container and pushes it, Figure 3.

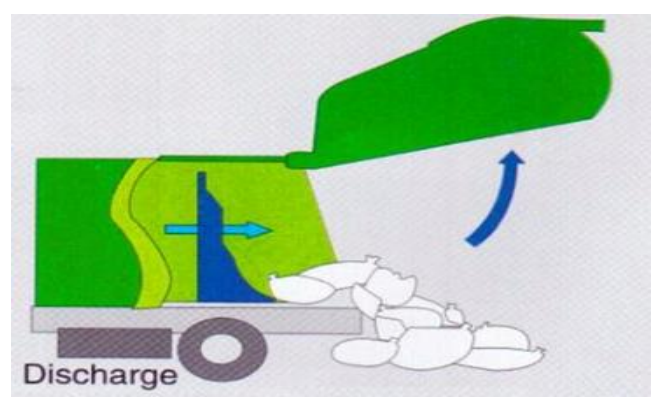

Fig. 3. The discharge of the municipal solid waste [5].

Other power and compaction mechanisms for rear-loading machines are shown in Figure 4. The degree of compaction achieved by these mechanisms can be $1: 3-1: 4$, bringing waste to a density of $0.6-0.8 \mathrm{t} / \mathrm{m}^{3}$. 
The diagram presented in figure 4 illustrates the unique packing mechanism, which was based loosely on Cyril Gollnick's original Leach Packmaster, but with some key differences. Where the Packmaster had utilized a single curved track and with swing link stabilizers, the new E-Z Pack featured two separate tracks (yellow highlights). The lower track was circuitous, and controlled the single blade during its movement in the hopper. One-way gates (red highlights) maintained proper movement of the blade as the hydraulic cylinders were reversed during the normal packing cycle. The latches could also be manually unlocked in the event of a jam which required reversing the cycle. The near-vertical upper track performed the function of stabilizing the blade. Only three cylinders were used in the entire body; one telescopic ejector cylinder, and two packing rams which doubled as tailgate lifts (a blocking pin was inserted into the roller track to effect lifting of the tailgate. A heavy-duty, fourpoint underbody latch secured the end gate structure to the body [6].

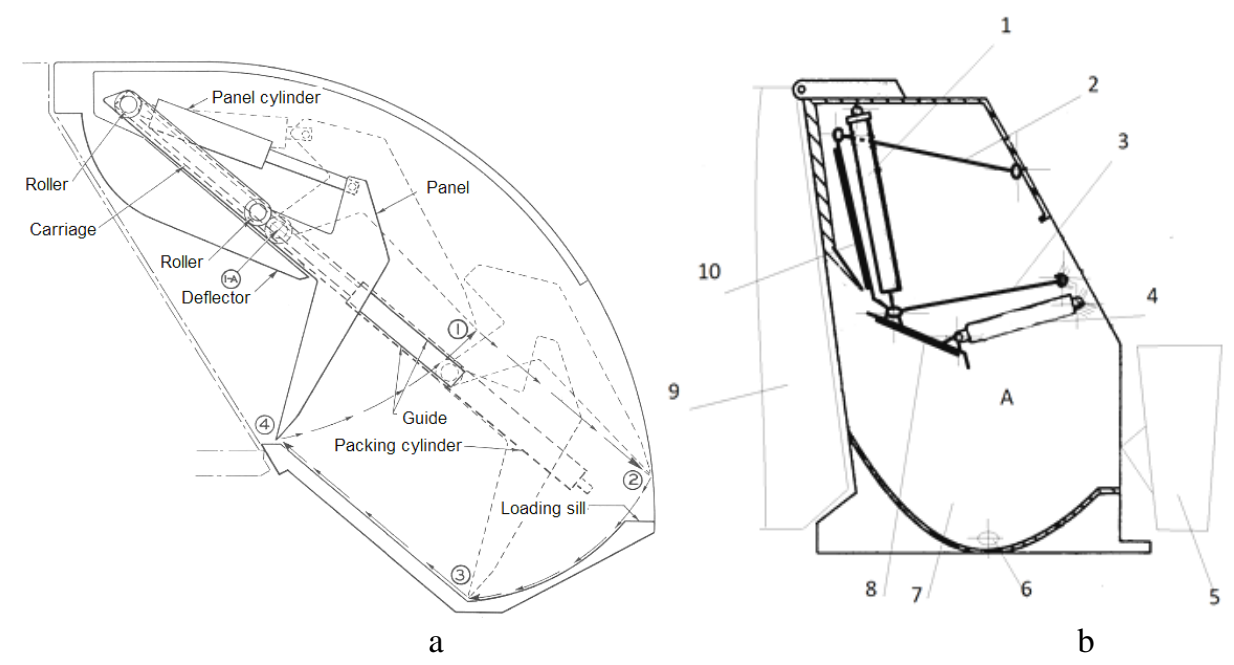

Fig. 4. The some compaction mechanisms of a MSW collection trucks [4, 7]: 1, 4- hydraulic cylinders; 2, 3swivel arms; 5- container; 7- reception tank; 8- mobile plate; 9- drum compaction; 10- compaction plate.

\section{RESULTS AND DISCUSSION}

The compacting system of Figure 1 and Figure 2 was schematized in the form of the mechanism of Figure 5 for which the kinematic analysis was performed. Points A, D, F and $\mathrm{H}$ represent fixed joints, while joints $\mathrm{C}, \mathrm{E}$ and $\mathrm{G}$ are movable when acting on the mechanism elements by means of hydraulic cylinders AC and HG. Couplings B and I are translation couples, representing the pistons of the hydraulic cylinders.

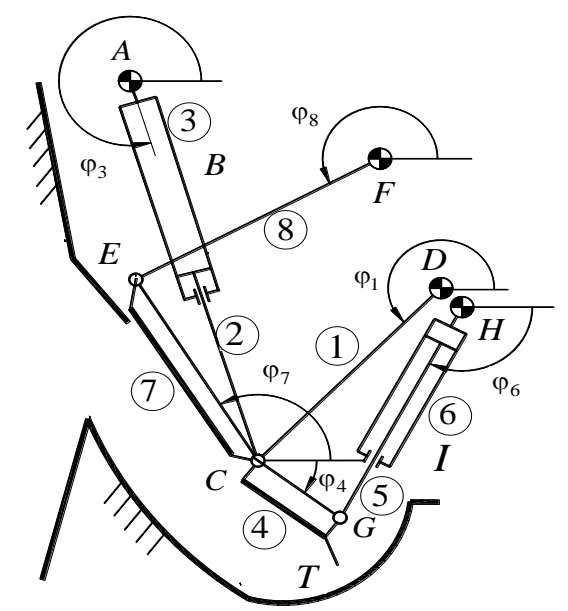

a

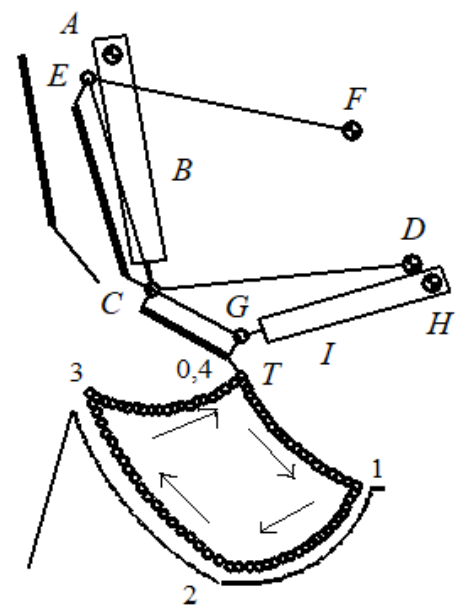

b

Fig. 5. The kinematic scheme of the press mechanism (a) and the movement diagram of the tracer point $\mathrm{T}$ (b) [7]. For the numerical analysis of the kinematics of the mechanism of Fig.5, the following constructive features were 
used:

1. the dimensions of the elements and the positions of the adjacent couplers are: $\mathrm{CE}=0.76 \mathrm{~m}, \mathrm{CD}=0.86 \mathrm{~m}$, $\mathrm{CG}=0.33 \mathrm{~m}, \mathrm{EF}=0.89 \mathrm{~m}, \mathrm{GH}=0.83 \mathrm{~m}, \mathrm{XD}=1 \mathrm{~m}, \mathrm{YD}=-0.73 \mathrm{~m}, \mathrm{XF}=-0.8 \mathrm{~m}, \mathrm{YF}=-0.27 \mathrm{~m}, \mathrm{XH}=1.07 \mathrm{~m}, \mathrm{YH}=-0.8 \mathrm{~m}$;

2. the initial position of the mechanism: $S_{230}=A C=0.66 \mathrm{~m}, \mathrm{~S}_{560}=\mathrm{GH}=0.83 \mathrm{~m}$;

3. working stroke of the hydraulic cylinder pistons: $\mathrm{C}_{23}=0.59 \mathrm{~m}, \mathrm{C}_{56}=0.39 \mathrm{~m}$;

4. the relative speeds between elements 2 and 3, respectively 5 and 6 (relative speeds in translational couples B and I): $\mathrm{v}_{23}= \pm 0.05 \mathrm{~m} / \mathrm{s}$ (the plus sign is considered when the piston rod comes out of the cylinder and the minus sign when the piston rod enters the cylinder), $\mathrm{v}_{56}= \pm 0.05 \mathrm{~m} / \mathrm{s}$;

5. the relative accelerations between elements 2 and 3, respectively 5 and 6 (relative accelerations in translational couples B and I): $\mathrm{a}_{23}=0 \mathrm{~m} / \mathrm{s}^{2}, \mathrm{a}_{56}=0 \mathrm{~m} / \mathrm{s}^{2}$.

For the structural analysis of the mechanism were determined the kinematic couplers, the mobile elements and the degree of mobility of the mechanism.

The mechanism shown in Figure 5 is a synchronous one in which the $\mathrm{CT}$ and CE compacting plates have synchronous motion impacted by the two hydraulic cylinders AC and HG respectively. The initial position of the mechanism is the high position in which both the AC cylinder and the HG cylinder are in the closed position so that the point $\mathrm{T}$, called the tracer, is in the 0 position. For each of the two hydraulic cylinders, the calculation program has 20 intermediate positions such that by opening the hydraulic cylinder $\mathrm{AC}$, the tracer point $\mathrm{T}$ follows the trajectory 0-1 from the figure in which the CT pickup plate starts to take over the accumulated municipal solid waste in the receiving part of the garbage truck, closing the connection to the exterior. From position 1 of the tracer point $\mathrm{T}$, there are another 20 intermediate positions of the $\mathrm{HG}$ cylinder that opens so that the $\mathrm{T}$ point follows the curve 1-2 in which the waste is partially precompacted. From this position restarts the AC cylinder lock, the residues being elevated and pushed over the previously picked up wastes and found in front of the inner plate in the collection bin. At this feed and precompaction also helps the EC plate that moves to the inside of the bin, the FECD quadrant with fixed F and D joints. During closing hydraulic cylinder AC, the tracer point $\mathrm{T}$ follows the curvilinear trajectory 2-3 from Figure 5b. Arrived in position 3, follow the HG hydraulic cylinder lock travel, the tracer point $\mathrm{T}$ retracts from position 3 to position 4 ( $\equiv$ to position 0 ). For these intermediate positions of the hydraulic cylinders, the calculation program made in the Matlab program can render the intermediate angles of the mechanism elements as well as the angular velocity and angular acceleration of these elements.

What interests the process is actually the position, velocity and acceleration of elements 4 and 7 that represent the waste pick up and compacting plates at the garbage truck which presents such a mechanism.

Figure 6 shows the graphs of velocity and angular acceleration of the mechanism elements for the 20 positions of the hydraulic cylinders in the normal working process (the trajectories of the curvilinear parallelogram in Figure $5 b$ ). It is found that for the positions of the trajectories $0-1$ and 2-3, the angular speeds of the element 4 (the pickup plate) are relatively constant, while for trajectories 1-2 and 3-4, angular velocities are very different from the others, with a positive sense (the closing stroke of the hydraulic cylinder HG) or negative (the opening stroke of the hydraulic cylinder HG).
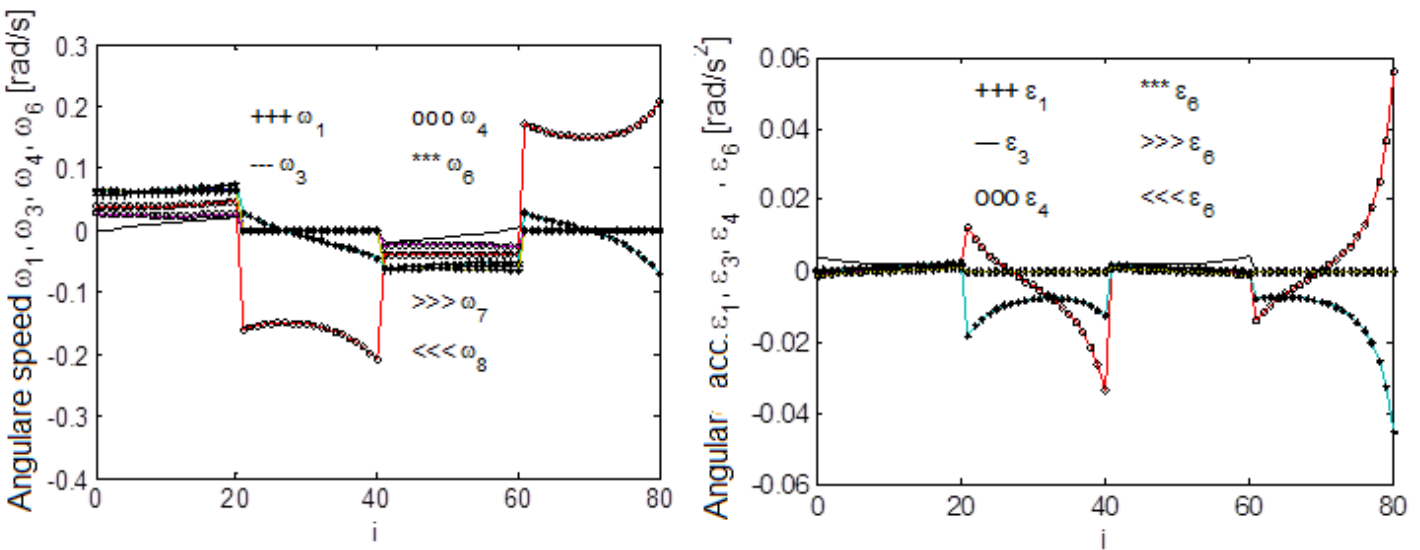

Fig. 6. Angular speeds and angular accelerations of the mechanism elements for a complete work cycle [7]. 
For a sinusoidal variation law of the movement of the two hydraulic cylinder rods, the speed and acceleration holographs of the tracer point T (the top of the pick-up and compaction plate) are shown in Figure 7.

There is a cyclical distribution of the T-point velocities on the horizontal and vertical axis necessary for a good takeover of the material in the vane without significant losses and a distribution of the bicycle accelerations that imprints different forces along the trajectory of the point.

The maximum T-point acceleration $\left(0.202598 \mathrm{~m} / \mathrm{s}^{2}\right)$ is recorded in zone 2-3 of the trajectory, where the resistance forces are maximum.
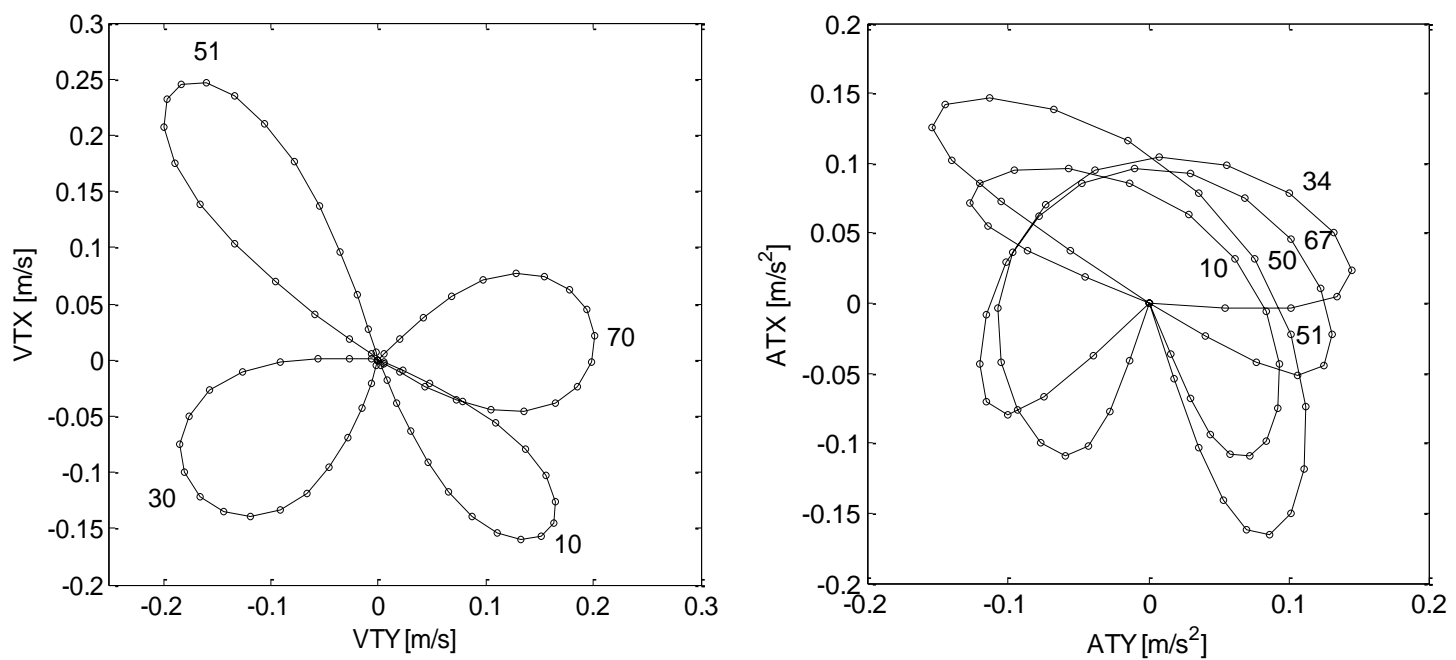

Fig. 7. Hodograph speeds and accelerations of tracer point $\mathrm{T}$ [7].

\section{CONCLUSIONS}

The mechanisms of the compaction plates of the garbage trucks are usually planar mechanisms with articulated bars driven by hydraulic cylinders. The movement of the elements of the mechanism must be correlated with the movement of the waste pick-up plate in the rear drum of the machine so as to take the material from the drum, raise it and push it over the previously picked up waste into the collection container. Thus, the top of the pickup plate follows predetermined trajectories along the trajectory, trajectories that can be determined by the kinematic analysis of the drive mechanism. The speed or acceleration of the plate or pick-up plates and compaction plates also follows predefined distributions depending on the hydraulic cylinders movement and the hydraulic system pressure.

In order to print a trajectory and gear and acceleration distributions to achieve a proper compaction process, it is necessary to introduce components into the hydraulic circuit to print different pressure in hydraulic cylinders over their stroke length.

Elucidation of the movement of the working organs of these mechanisms is necessary for a good understanding of their operation, but especially for redesigning and improving their functional parameters for a low-energy and low-energy operation.

\section{REFERENCES}

[1] UNEP (United Nations Environmental Programme), Environmentally Sound Approach for Sustainable Urban Waste Management. Available at: http://www.gdrc.org/ uem/waste/planning/waste-planning-body.pdf, 2002 (24.06.2019).

[2] UNEP (United Nations Environmental Programme) and Silva, D., Estado do meio ambiente e retrospectivas políticas: 1972-2002 - Áreas Urbanas (State of the environment and policy retrospective: 1972-2002 - Urban Areas). New York: UNEP, 2004. 
[3] Coffey, M., Coad, A., Collection of municipal solid waste in developing countries, United Nations Human Settlements Programme (UN-HABITAT), Gutenberg Press, Malta, 2010.

[4] http://www.eagle-hydraulic.com/refuse_trucks.html (24.06.2019).

[5] http://www.sztrucks.com/3CBM-waste-collecting-garbage-compactor-truck_p23.html (24.06.2019).

[6] Classic Refuse Trucks E-Z PACK, http://www.classicrefusetrucks.com/albums/(24.06.2019).

[7] Moise, V., The synthesis of plane mechanisms with articulated bars. Applications in Matlab. Printech Publishing Housing, Bucharest, 2018. 